\title{
Impact of Simulated Electronic Health Records on Informatics Competency of Students in Informatics Course
}

\author{
Jeeyae Choi ${ }^{1}$, Lisa Anne Bove ${ }^{1}$, Valerie Tarte ${ }^{1}$, Woo Jung Choi ${ }^{2}$ \\ 'School of Nursing, College of Health and Human Services, University of North Carolina Wilmington, Wilmington, NC, USA \\ ${ }^{2}$ Transform Alliance for Health Clinic, Newton, MA, USA
}

Objectives: Nursing has embraced online education to increase its workforce while providing flexible advanced education to nurse professionals. Faculty use virtual simulation and other adaptive learning technologies to enhance learning efficiency and student outcomes in online courses. The purpose of this study was to assess the impact of simulated Electronic Health Records (EHRs) on informatics competency in a graduate online informatics course. Methods: A two-group independent measures study design was adopted to assess students' perception of a simulated EHR while comparing differences in informatics competencies between an intervention group and a control group. A simulated EHR assignment was provided to students in the intervention group, and a paper assignment was provided to those in the control group. The informatics competency of the students was measured using the Self-Assessment of Informatics Competency Scale for Health Professionals (SICS). Results: Students who were enrolled in a family nurse practitioner program in fall of 2019 participated in this study $(n=39)$. The students expressed positive perceptions of a simulated EHR experience. The SICS results indicated that students in the intervention (simulated EHR) group showed higher informatics competency than those in the control group. Conclusions: The positive results of this study support incorporating simulated EHR exercises in online courses. Higher informatics competency in the intervention group implies that the use of simulated EHR facilitated learning of complicated informatics concepts.

Keywords: Online Education, Online Learning, Electronic Health Record, Simulation Training, Informatics

Submitted: October 7, 2020

Revised: November 16, 2020

Accepted: November 24, 2020

\section{Corresponding Author}

Jeeyae Choi

School of Nursing, College of Health and Human Services, University of North Carolina Wilmington, 601 South College Road, Wilmington, NC 28403-5995, USA. Tel: +1-910-962-2487, E-mail: choij@uncw.edu (https://orcid.org/0000-0001-7287-6384)

This is an Open Access article distributed under the terms of the Creative Commons Attribution Non-Commercial License (http://creativecommons.org/licenses/by$\mathrm{nc} / 4.0 /$ ) which permits unrestricted non-commercial use, distribution, and reproduction in any medium, provided the original work is properly cited.

(C) 2021 The Korean Society of Medical Informatics

\section{Introduction}

Due to a nursing faculty shortage nationwide and demands for flexible learning $[1,2]$, nursing has had to embrace online education to accommodate a growing number of potential students [3]. Advances in information and communication technology have made high-quality online courses a feasible option in a versatile learning environment [4,5]. Online education has shifted the focus of nursing faculty to continuously enhance online learning using technologies for students to bridge the gap between knowledge acquisition and practice. In online nursing courses, web-based and virtual simulation technologies are used to improve student learning efficiency 
[6-8].

Online learning focuses on individual students, is speedy and flexible in time and place, enhances knowledge through easy access to information, and facilitates interaction through discussion forums and collaboration. However, online learning is vulnerable to the criticisms that it is simply a different delivery mechanism for existing methods of learning, that it lacks personal interactions and a learning community, that it is subject to technical problems, and that it is ineffective when hands-on practical skills need to be learned $[9,10]$. In response to these criticisms, web-based and virtual simulation have been adapted to maximize learning efficiency for online nursing curricula.

A graduate online informatics course was developed for a Family Nurse Practitioner (FNP) program at a university in North Carolina. While the course has been well received, the motivation for this study is rooted in the concern that students struggle to apply sophisticated and complex informatics concepts and knowledge in practice. A simulated hands-on experience incorporated into the course might facilitate student application of knowledge, advance skills, and improve clinical decision-making based on informatics.

The purpose of this study was to assess the impact of a simulated Electronic Health Record (EHR) experience in a graduate online informatics course. Specific outcomes were measured to answer the following research questions: (1) What is the students' perception of a simulated EHR? (2) What are the Informatics Competency Scale' scores? (3) What is the difference between an intervention and control group on the Informatics Competency Scale' score?

\section{Methods}

\section{Study Materials}

EHRs have become the major source of patient information and documentation in healthcare, and they support the quality and safety of care [11]. With expanding use of EHRs, the integrity and quality of data and information input and shared by clinicians is becoming important. Well-structured EHRs have been proven to improve the quality of patient care [12]. However, there are growing concerns that clinicians misunderstand and misuse some functions of EHRs, supporting the need for informatics education and training by simulation [13]. Thus, we adapted simulated EHR as a hand-on experience in this course.

DocuCare by Wolters Kluwer is a simulated EHR developed for academic use [14]. It allows students to learn how patient data and information are constructed and encourages critical thinking about patient documentation using patient scenarios in a safe and true-to-life setting while allowing instructor feedback [14]. It was hypothesized that when DocuCare is used in a graduate informatics course, it would have a synergistic effect on student learning.

\section{Study Design and Setting}

A two-group independent measures design was utilized to test the impact of a simulated EHR experience in a graduate online informatics course.

A graduate nursing informatics course for an FNP program ran on the Canvas platform, a cloud-based e-learning management system in the Fall 2019 semester. The course materials and structures of the intervention and control groups were the same. All students participated in five interactive discussion forums, took two exams, and submitted two paper assignments. In the intervention group, one of the two paper assignments was replaced with a DocuCare (simulated EHR) assignment.

\section{Study Sample}

Students enrolled in the course in the Fall 2019 semester were the sample of the study. The student participants were randomly assigned by the automatic grouping of Canvas to either the intervention group or the control group.

\section{Study Instruments}

Survey questionnaires (a total of six items with a 4-point Likert-scale) were developed by a research team for the research question, "What is the students' perception of a simulated EHR?" The Self-Assessment of Informatics Competency Scale for Health Professionals (SICS) [15] tool was used to collect data for the research questions, "What are the Informatics Competency Scale's scores?" and "What is the difference between the intervention group and the control group on the Informatics Competency Scale' score?" The SICS (total 18 items with 5-point Likert-scale) has strong reliability (Cronbach's alpha $=0.93$ ) and measures three domains of informatics competency: basic computer skills, role, and applied computer skills (clinical informatics).

\section{Study Procedure}

This study received approval through the University's Institutional Review Board (No. 19-0251) as exempt research.

\section{1) Scenario customization}

Ten built-in patient scenarios were taken from DocuCare and customized for students in an FNP program. All scenar- 
ios were modified following a patient visit to an outpatient clinic to see an FNP. Each scenario's health information, such as vital signs, lab data, and nursing orders were simulated accordingly. Modified scenarios and simulated health data were displayed for students' use in DocuCare.

\section{2) DocuCare (simulated EHR) assignment}

Each scenario in DocuCare included vital signs, laboratory data (e.g., urine analysis, complete blood count, X-ray), and some nursing orders with a brief explanation of the reason for the patient's visit. Each student in the intervention group was trained on how to use DocuCare (e.g., reviewing patients' information, ordering labs, writing assessment notes) through a 15-minute instruction video one week before starting the assignment. Also, written instructions on the DocuCare assignment were posted on Canvas. Once students accessed DocuCare, they were asked to select one from 10 customized scenarios. They were asked to identify the attributes of data and information from DocuCare and then synthesize knowledge (e.g., care plans) based on the identified data and information. Although time varied for individual students, it took about one hour to work through one scenario. The students were required to write a structured report after the DocuCare experience.

The students in the control group, the non-simulated EHR group, were assigned a paper assignment. They wrote a descriptive report of a computerized health information system of their own choosing to discuss during the same assignment period. Written instructions for this paper assignment were also posted on Canvas for this group.

\section{3) Data collection}

Two survey questionnaires were utilized to collect data at the end of the semester. Students in the intervention group completed two surveys: the perception of a simulated EHR (Likert scale of 7 questions with comment) and the SICS. Students in the control group completed only the SICS.

\section{Data Analysis}

IBM SPSS version 25 (IBM, Armonk, NY, USA) was used to perform statistical analyses. Descriptive data were used to analyze the students' demographic data. Levene's test was used to test the assumption of normality. To facilitate comparisons across the informatics competency scale (SICS), the mean scores of each sub-domain and the full scale were calculated for each group. An independent $t$ test was used to analyze differences between the intervention and control groups.

\section{Results}

There were 40 students enrolled in the course, and all participated in this study, although one student later withdrew consent for their data to be used in the analysis. There were 37 (94.9\%) female students and only 2 (5.1\%) male students. Thirty-eight students (97.4\%) were white, not Hispanic, and only $1(2.6 \%)$ was black, not Hispanic. Twenty-six (66.7\%) students were ages of 20 to 39, and 13 (33.3\%) of them were over 40 years old. Half of the students $(\mathrm{n}=19,48.7 \%)$ reported that they had 2 to 5 years of nursing experience. Most students $(n=38,97.4 \%)$ indicated that they used a computer several times per day, and a similar number of students $(\mathrm{n}=$ $37,94.9 \%$ ) indicated that they had been using a computer for longer than 2 years. Table 1 shows the characteristics of the students in the intervention and control groups.

\section{Perception of a Simulated EHR}

Students in the intervention group indicated that the simu-

Table 1. Students' characteristics $(n=39)$

\begin{tabular}{lcc}
\hline \multicolumn{1}{c}{ Variable } & $\begin{array}{c}\text { Simulated EHR } \\
(\mathrm{n}=19)\end{array}$ & $\begin{array}{c}\text { Non-simulated } \\
\text { EHR }(\mathrm{n}=20)\end{array}$ \\
\hline Gender & $18(94.7)$ & $19(95)$ \\
Female & $1(5.3)$ & $1(5)$ \\
Male & & \\
Race/ethnicity & $1(5.3)$ & $0(0)$ \\
Black, not Hispanic & $18(94.7)$ & $20(100)$ \\
White, not Hispanic & & \\
Age (yr) & $7(36.8)$ & $7(35)$ \\
$20-29$ & $5(26.3)$ & $7(35)$ \\
$30-39$ & $7(36.8)$ & $6(30)$ \\
$40-49$ & & \\
Nursing experience (yr) & $10(52.6)$ & $9(45)$ \\
$2-5$ & $5(26.3)$ & $5(25)$ \\
$6-10$ & $4(21.1)$ & $6(30)$ \\
$>10$ & & \\
Computer use (frequency) & $18(94.7)$ & $20(100)$ \\
Several times/day & $1(5.3)$ & $0(0)$ \\
Several times/week & & $1(5)$ \\
Computer experience (yr) & $1(5.3)$ & $19(95)$ \\
In the last 6 month & $18(94.7)$ & \\
$>2$ &
\end{tabular}

Values are presented as number (\%).

EHR: Electronic Health Record. 
lated EHR assignment was an enjoyable experience and that they learned something related to the real world. They also indicated that the simulated EHR helped them to understand concepts in informatics. Table 2 shows students' perception of a simulated EHR.

\section{Self-Assessment of Informatics Competency Scale for Health Professionals}

Overall, the students' mean SICS score in the intervention group was $24.84 \pm 3.79$, and that of the control group was $22.29 \pm 3.79$. The mean score of three subscales, namely, basic computer skills, role, and applied computer skills/clinical informatics, were 4.61, 2.93, and 17.29 in the intervention group and 4.08, 2.66, and 16.19 in the control group, respectively. The total and subscale means in the intervention group showed higher competency scores than those in the control group. Table 3 shows the detailed SICS scores for each group. The $t$ test indicated statistical differences

Table 2. Perception of simulated EHR in the intervention group ( $\mathrm{n}=19)$

\begin{tabular}{lc}
\hline \multicolumn{1}{c}{ Survey } & \multicolumn{1}{c}{ Score } \\
\hline I generally enjoy using Simulated EHR & $2.23 \pm 0.68$ \\
I found the scenarios and activities in Simulated & $2.23 \pm 0.52$ \\
EHR interesting. & $2.27 \pm 0.45$ \\
Simulated EHR was easy to use. & $1.91 \pm 0.68$ \\
$\begin{array}{l}\text { I liked the colors, images, and setup of Simu- } \\
\text { lated EHR. It was pleasing to the eye. }\end{array}$ & \\
$\begin{array}{l}\text { I understand the concepts in informatics be- } \\
\text { cause I used Simulated EHR. }\end{array}$ & \\
\hline & \\
I felt that what I was learning in informatics was & $2.55 \pm 0.52$ \\
related to the real world.
\end{tabular}

Values are presented as mean \pm standard deviation.

Each item is scored as 0 (strongly disagree), 1 (disagree), 2 (agree), or 3 (strongly agree).

EHR: Electronic Health Record. between groups in total $(p=0.04)$ and the subscales of basic computer skills $(p=0.03)$ and role $(p=0.09)$.

\section{Discussion}

This study demonstrated the impact of simulated EHR on learning in a graduate online informatics course. We adopted DocuCare (simulated EHR) to improve informatics competency. DocuCare with customized scenarios was successfully presented to students enrolled in an FNP program. Overall, the results show that experiencing simulated EHR increased informatics competencies.

About $97 \%$ of students who participated in this study were frequent computer users (several times per day) with more than 2 years of computer experience. This implies that most students were computer literate, which may explain the high scores in a sub-domain of the informatics competency scale, basic computer skills, for both the intervention and control groups (Table 3).

Students who experienced the simulated EHR showed higher informatics competency than those in the control group. Both the total informatics competency and competency in each of the three sub domains were high in those who experienced simulated EHR. Activities such as identifying a patient's important data and information, using a decision support system to visualize blood pressure patterns over a week, and synthesizing new care plans in the complicated EHR through a DocuCare assignment could enhance overall informatics competency. Studies support the rationales and outcomes of this study, which highlight the importance of a simulated EHR experience in nursing curricula and how practicing using EHRs by simulation could improve informatics competency [16-18]. Although the informatics competency measuring tool (SICS) only measures the level of self-confidence, not an absolute value [15], a benchmark for the informatics competency of students in an FNP program in this university was set.

High informatics competency in total and the basic com-

Table 3. Informatics competency score $(n=39)$

\begin{tabular}{lcccc}
\hline \multicolumn{1}{c}{ Sub-domain } & Simulated EHR & Non-simulated EHR & $t$ & $p$-value \\
\hline Basic computer skills (4 items) & $4.61 \pm 0.70(0-6.03)$ & $4.08 \pm 0.76(0-6.03)$ & 2.24 & 0.03 \\
Role (2 items) & $2.93 \pm 0.44(0-3.36)$ & $2.66 \pm 0.55(0-3.36)$ & 1.69 & 0.09 \\
Applied computer skills/clinical informatics (12 items) & $17.29 \pm 3.42(0-26.81)$ & $16.19 \pm 3.25(0-26.81)$ & 1.02 & 0.31 \\
Total & $24.84 \pm 3.79(0-36.20)$ & $22.29 \pm 3.79(0-36.20)$ & 2.09 & 0.04 \\
\hline
\end{tabular}

Values are presented as mean \pm standard deviation (range).

Each item is scored as 0 (not competent), 1 (somewhat competent), 2 (competent), 3 (proficient), or 4 (expert). 
puter skills and the role sub-domains, indicate the positive impact of a simulated EHR on informatics learning in a graduate online informatics course. Further, students in the simulated EHR group expressed between "agree" and "strongly agree" for two questions, "I felt that what I was learning in informatics was related to the real world" and "I understand the concepts in informatics because I used Simulated EHR" in the survey regarding their perception of the simulated EHR (Table 2). This reveals the positive impact of simulated EHR on informatics learning in this course.

Two major limitations were the small sample size $(\mathrm{n}=39)$ and skewed students' characteristics, which misrepresented the true makeup of the target population. Greater representation of ethnic backgrounds and males might generate different results. Also, if hands-on experience using simulated EHR was provided more than once a semester, outcomes might be different. The generalization of these study findings should be limited until more studies with larger samples are conducted.

In conclusion, given demands for the improvement of online courses, including informatics courses, a study was conducted to improve the informatics competency of students in a graduate online informatics course using simulated EHR. Hands-on experience was developed with DocuCare (simulated EHR) and successfully provided to students in an FNP program. The study results demonstrated that experiencing simulated EHR increased the students' informatics competency and positively impacted learning of informatics concepts. The informatics competency assessed can be a benchmark for a graduate online informatics course developed for students in an FNP program.

Many nursing courses are moving to online delivery due to the shortage of nursing faculties and the demand for flexible learning. The current study's approach and results can be used to facilitate the development of effective new online courses while enhancing existing ones.

\section{Conflict of Interest}

Jeeyae Choi is an editor of Healthcare Informatics Research; however, she did not involve in the peer reviewer selection, evaluation, and decision process of this article. Otherwise, no potential conflict of interest relevant to this article was reported.

\section{Acknowledgments}

This study was supported by the Academic Partnerships
Faculty Research Grant Program (No. G58045).

\section{ORCID}

Jeeyae Choi (https://orcid.org/0000-0001-7287-6384)

Lisa Anne Bove (https://orcid.org/0000-0002-7761-2326)

Valerie Tarte (https://orcid.org/0000-0003-4654-9747)

Woo Jung Choi (https://orcid.org/0000-0003-3244-7758)

\section{References}

1. Lewis PA, Tutticci NF, Douglas C, Gray G, Osborne Y, Evans K, et al. Flexible learning: Evaluation of an international distance education programme designed to build the learning and teaching capacity of nurse academics in a developing country. Nurse Educ Pract 2016;21:59-65.

2. Yusuf J, Prasad D, Bhartu D. Blending media for flexible learning at a regional university. Int J Instr Technol Distance Learn 2017;14:33-42.

3. Gaston T, Lynch S. Does using a course design framework better engage our online nursing students? Teaching and Learning in Nursing 2019;14:69-71.

4. Foronda C, Bauman EB. Strategies to incorporate virtual simulation in nurse education. Clin Simul Nurs 2014;10:412-8.

5. Voutilainen A, Saaranen T, Sormunen M. Conventional vs. e-learning in nursing education: a systematic review and meta-analysis. Nurse Educ Today 2017;50:97-103.

6. Chung C, Cooper SJ, Cant RP, Connell C, McKay A, Kinsman L, et al. The educational impact of web-based and face-to-face patient deterioration simulation programs: an interventional trial. Nurse Educ Today 2018; 64:93-8.

7. Foronda CL, Alfes CM, Dev P, Kleinheksel AJ, Nelson DA Jr, O’Donnell JM, et al. Virtually nursing: emerging technologies in nursing Education. Nurse Educ 2017;42: 14-7.

8. Verkuyl M, Hughes M, Tsui J, Betts L, St-Amant O, Lapum JL. Virtual gaming simulation in nursing education: a focus group study. J Nurs Educ 2017;56:274-80.

9. Arkorful V, Abaidoo N. The role of e-learning, advantages and disadvantages of its adoption in higher education. Int J Instr Technol Distance Learn 2015;12:29-42.

10. Macleod J, Kefallonitis E. Trends affecting e-learning experience management. In: Kavoura A, Sakas D, Tomaras P, editors. Strategic innovative marketing. Cham, Switzerland: Springer; 2017. p. 753-8. 
11. Hardiker NR, Dowding D, Dykes PC, Sermeus W. Reinterpreting the nursing record for an electronic context. Int J Med Inform 2019;127:120-6.

12. Milano CE, Hardman JA, Plesiu A, Rdesinski RE, Biagioli FE. Simulated electronic health record (Sim-EHR) curriculum: teaching EHR skills and use of the EHR for disease management and prevention. Acad Med 2014; 89:399-403.

13. March CA, Scholl G, Dversdal RK, Richards M, Wilson LM, Mohan V, et al. Use of electronic health record simulation to understand the accuracy of intern progress notes. J Grad Med Educ 2016;8:237-40.

14. Wolters Kluwer Health Inc. Lippincott' DocuCare [Internet]. Philadelphia (PA): Wolters Kluwer Health Inc.; c2020 [cited at 2020 Dec 28]. Available from: https:// thepoint.lww.com/docucare.

15. Yoon S, Shaffer JA, Bakken S. Refining a self-assessment of informatics competency scale using Mokken scaling analysis. J Interprof Care 2015;29:579-86.

16. Forman TM, Flores D, Miller AS. An integrative literature review of the use of electronic health records for clinical nursing education. J Inform Nurs 2020;5:28-44.

17. Repsha C, Morse B, Lee SE, Katz J, Burrows E, Teates J. Use of a simulated electronic health record to support nursing student informatics knowledge and skills. Comput Inform Nurs 2020;38:55-9.

18. Wilbanks BA, Watts PI, Epps CA. Electronic health records in simulation education: literature review and synthesis. Simul Healthc 2018;13:261-7. 